\author{
Research on Effects of Transnational Operation of the SME Cluster \\ Bing Guan ${ }^{1, a^{*}}$ and Huijuan Sun ${ }^{2, b}$ \\ ${ }^{1}$ School of Economics, Harbin University of Commerce, P. R. China, 150028 \\ ${ }^{2}$ Graduate School, Harbin University of Commerce, P. R. China, 150028 \\ agbwyy@sina.com, bsunhuijuan1993@163.com \\ *The Corresponding author
}

Keywords: SME; Industry cluster; Trans-national operation

\begin{abstract}
With the global economic integration, the transnational operation of enterprises cluster gradually shows its unique advantages and becomes the best choice for the small and medium-sized enterprises to enter international marketplace. This paper analyzes the operation effects of the small and medium enterprises cluster, e.g. accumulated effect, brand effect, structure advantage, cost advantage etc. Based on the analysis, it puts forward the strategies for the transnational operation of the small and medium enterprises cluster of our country.
\end{abstract}

\title{
Introduction
}

As new organization methods, the cluster of small and medium-sized enterprises has provided plenty of vigor for the development of small and medium-sized enterprises. It is the source of rejuvenation of SMEs. In this organization form, the SMEs mutually compete against and cooperate with each other within the cluster on the basis of specialization. This kind of relation not only helps to improve the relative competitiveness of enterprises but also make small and medium-sized enterprises obtain the strengths in international competition. Especially, the SME cluster plays an important role in the course of transnational operation.

\section{Analyses on the Effects of Transnational Operation of the SME Cluster}

It is undoubtedly the effective means that small and medium-sized enterprises improve their competitiveness in the international competition is to join the cluster of SMEs. The strong power and the great competitiveness of the cluster are quite obvious compared with single enterprises.

Cluster Effect. The trans-national operation of the SME cluster can release a kind of cluster effect. This kind of cluster effect is not only the rational foundation of the SME cluster existing, but also the motive force that the SME cluster is being improved constantly. It reflects in three aspects:

External Economy. When social income of an economic activity is greater than private income, there is external economy. The external economy of SME cluster means that owing to the concentration of enterprises in the region, the division of labor in society is deepened, the connections among the enterprises become closer and the regional utilization of resources is strengthened. All these lead to economizing on capital. The external economy and convenience shows in access convenience, convenience of enterprises reborn, convenience of innovation as well as the convenience of forming and accumulating of social capital.

Joint Action. The joint action in the cluster of small and medium-sized enterprises can improve the technological ability of the cooperative manufacturers, and also can help the cluster to grow rapidly and obtain enhanced competitiveness. This kind of action is conscious and purposeful activity among all principals. It is a dynamic and initiative cluster effect.

System Effect. As a whole, this is a new organization pattern which connects enterprises and market. In the cluster, social capitals are progressively formed and accumulated. The culture atmosphere of sincerity and cooperation helps to unite the market, standardize product standard and pursue common trade mark and specialized technology. The expenses of signing and executing contracts among every manufacturer in the cluster are relatively small. Another important matter is 
that government may help promote the development of cluster by making particular cluster policy and forming a favorable system etc.

Cost Effect. The SME cluster has the cost advantage over a single small and medium-sized enterprise in the course of transnational operation. The cluster can reduce information expenses, labor cost and save the costs of circulation. The enterprises in the cluster have formed efficient system of specialization and coordination and can reduce the expenses of procurement, transportation and storage considerably.

Brand Effect. The investigation shows that if we put the retail shop that sells like products together, the sales amount and profits of each retail shop are higher than that of scattered shops, because the gathered retail shops are often easy to obtain consumer's cognition, and attract more customers to go to the place where like products are sold to buy the goods they need. For the small and medium-sized enterprises, it is vitally important to obtain cognition and approval of the international market and to take advantage of the promotion of cluster brand in the local area in order to realize the internationalized operation.

Structural Advantage. The SME cluster is a flexible production system. This kind of production system makes the SME cluster adapt to the current complicated economic environment to meet the requirements of various, ever-changing consumption demand and increasingly shortening products life cycle. Facing the intense international competition, the SME cluster is capable to catch more opportunities and manage to occupy greater market share to bring enable benefit to every enterprise in the cluster.

Other Effects. The SME cluster type trans-national operation still has some other effects which individual enterprise does not possess.

Table 1 Other Effects of Transnational Operation of the SME Cluster

\begin{tabular}{|c|c|}
\hline Effects & Features \\
\hline Innovation Effect & $\begin{array}{c}\text { Capability of innovation, great attraction to scientific } \\
\text { and technological talent. }\end{array}$ \\
\hline Social capital effect & $\begin{array}{c}\text { Trustworthy, cooperative, standardized among the } \\
\text { enterprises in the cluster. }\end{array}$ \\
\hline Knowledge overflowing Effect & $\begin{array}{c}\text { Fast spreading of Collective learning process, } \\
\text { information, knowledge and practice in the whole } \\
\text { cluster. }\end{array}$ \\
\hline $\begin{array}{c}\text { Drawing effect of core } \\
\text { enterprise }\end{array}$ & $\begin{array}{c}\text { The enterprises are closely connected and around core } \\
\text { enterprise in particular area. They specialize in the } \\
\text { production for the core enterprise. }\end{array}$ \\
\hline
\end{tabular}

The above effects are sources of forming competitive advantage among the enterprises in the cluster. It is significant for the SMEs to choose the Cluster-type Transnational Operation method, and this will greatly enhance the core competitiveness of the SMEs.

\section{The SME Cluster Transnational Operation Strategies in China}

Combination of Cluster and Internationalization Strategy. When SME chose to enter clusters selectively, it should integrate the cluster strategy and internationalization strategy to form a strategic combination, guiding the development of enterprises. Introduction of foreign advanced technology and the development of foreign market are the first step for enterprises cluster to implement internationalization strategy. After some foreign investments are attracted by one enterprise, more foreign investments will be attracted, thereby, it can promote internationalization development of other enterprise in the same industry. Introduction of technology and international trade are the link to these two strategies. The combination of cluster and internationalization strategy accords with the logical development order of SME. 
Establishment of United Mutual Aid Organization within Cluster. The untied mutual aid organization plays an important role in the cluster. Only through such organization, the enterprises can form a whole community effectively. Japan pays great attention to the establishment of aid organization, and set up a variety of enterprises aid organization, such as Business United Committee, Commerce and Industry Construction Association and so on, which take charge of promoting the communication among the enterprises within the cluster periodically and they can reduce the factor searching costs through exchanging production factors among the enterprises. However, in our country, there are not any such organizations in most enterprises, or there only exist some official organizations that function ineffectively. We should establish some enterprises aid organization based on market-oriented mechanism.

Building International Cluster. Through the cluster transnational operation strategy, the SMEs possess the advantage to participate in the international competition, and also lay good foundation for international development. Since the cluster and SME are close connected, from other point of view, the SME cluster has become the carrier of internationalization of SMEs. Through the whole cluster's internationalization, SME can achieve the goal of internationalization indirectly.

Introducing of International Talent and Information Use. To overcome the regional cultural limitation, SME cluster eagerly needs to introduce transnational operation talent. Although proficient of the local affairs is the advantage for local staff, however, it is not enough to deal with international affairs only with local management knowledge. So the international management talents who possess strategic vision and can judge the situation from the whole are badly needed. The concerning departments of government should provide perfect information consultation and social service system to facilitate the SMEs to obtain technology, market, talent and information. The SME' transnational operation strategy, especially for effecting industrial cluster investment, will need the services of information, personnel training and psychology consultation, among which information service is the most important. The government should follow the principle of "instruction and coordination as the main method and participate as the subsidiary method", and set up a multi-layer and high-efficiency SME transnational operation service system. For example, the SME consociation cooperation organizations play an important function in helping the SME cluster to invest overseas.

The International Financial Standards and International Financing. The SME financing methods within cluster mainly comes from the domestic market. However, with the development toward international marketplace, the financing channels also should be expanded to foreign marketplace. Meanwhile, capital internationalization requires the various enterprises' financial statements to meet the international standards, and should report the enterprises financial situation honestly and timely. Enterprise financial standards contribute to the establishment of unified enterprise financial situation assessment system in order to provide standards for comparison. The financial statements which based on international standards can help foreign investor understand the operation state of enterprises, increase creditability. The government should speed up and perfect the domestic financial service system, provide more services such as favorable loan, guarantee and insurance, encourage domestic commercial bank and insurance company to set up branches in the regions which have many SMEs, and help investors deal with daily financial affairs and finance problems.

Cultivating and Upgrading Clusters Brand. Brand plays a decisive role in attracting consumers and expanding customer base. In addition to some factors such as good quality products and rational cost performance, a lot of brand maintenance costs such as advertising fees, maintenance cost are also needed to cultivate a brand. It is far from the ability of an individual SME. What is more, individual enterprise's brand only represents the product of its own, when making purchase decision, customers will compare different brands of the same product. However, cluster's brand represents all the products of the enterprises cluster, which can help to lower customer's research information cost. The cluster brand that enjoys great reputation can easily attract a large number of customers, meanwhile, can also easily attract other SMEs to join in the cluster. Therefore, the cluster should make great efforts to cultivate and upgrade its own brand, and avoid things that harmful to cluster brand happening. 
Constructing Transnational Operation Managing System. Currently, our government adopts the examining and approval system in the SME' oversea investment, which exist a series of problems such as rigorous checking processes and the adding transaction costs will restrict the enterprise's decision-making power and delay the most appropriate investment time. Adopting the multiple examining procedure of invest activities is quite inconvenient for small and medium enterprises. So, we should further perfect the SME cluster transnational operation managing system.

Geographically concentration and similar operations contribute to the formation of cluster' own culture, which can exert a subtle influence on cluster development by shaping the conception, behavior and habits of the staff (particularly entrepreneurs) in the cluster.

\section{Conclusions}

Internationalization is not only one of characteristics of enterprise's high development, but also the goal that SME need to achieve currently. Cluster-based transnational operation strategies will enable the SME accumulate sufficient strength and occupy competitive advantages when facing the intense international competition.

\section{References}

[1] Harri Lorentz, Olli-Pekka Hilmola. Cluster Analysis Application for Understanding SME Manufacturing Strategies[J]. Expert Systems with Applications. 2016(09)

[2] Daniela Corsaro, Chiara Cantu, Annalisa Tunisini. Actors' Heterogeneity in Innovation Networks[J]. Industrial Marketing Management. 2012(05)

[3] Stefano Comino, Clara Graziano. How Many Patents Does It Take to Signal Tech-innovation Quality[J]. International Journal of Industrial Organization. 2015(09)

[4] Wu Hanfen, the Causes and Effects of SME Cluster. Enterprise Reform and Management.2015(04) 